\title{
Improving Students' Oral Communication Skills Through an Interdisciplinary Problem-Based Learning Opportunity in a Sport Management Course
}

\author{
Charlie Song ${ }^{\text {a }}$, Heather Riddell b, Stuart Ryan c, ${ }^{*}$ \\ a Department of Administration and Law, University of West Florida, Pensacola, Florida, United States \\ ${ }^{b}$ Department of Communication, University of West Florida, Pensacola, Florida, United States \\ c Department of Teacher Education and Educational Leadership, University of West Florida, Pensacola, Florida, United States \\ *Corresponding author Email: sryan@uwf.edu \\ DOI: https://doi.org/10.34256/ijpefs2133
}

Received: 17-04-2021, Revised: 28-06-2021; Accepted: 03-07-2021; Published: 08-07-2021

\begin{abstract}
This study adopted several pedagogical foundations to determine if an interdisciplinary, problem-based learning (PBL) opportunity applied to teaching sport marketing would improve student' individual and group oral communication skills. Faculty from two departments collaborated to create an assignment that was a hands-on class project designed around formative assessment, lecture intervention, and final PBL deliverable. The PBL and interdisciplinary design addressed the need for enhanced communication skills in the sport management industry. The study results indicate a successful development of the students' data analysis and presentation skills. Findings confirm an interdisciplinary approach to PBL by implementing communication skill development across disciplines.
\end{abstract}

Keywords: Oral communication skills, Interdisciplinary design, Problem-solving learning, Self-reflection, Video

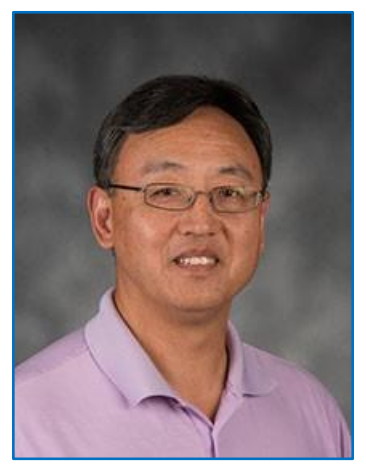

Dr. Charlie Song is an associate professor in the Department of Administration and Law and the coordinator of the Sport Management program at the University of West Florida. He earned his Ed.D. in Sport Administration/Management and M.S. in Physical Education from Texas A\&M University. His research interests include social and economic impact of sports megaevents, sport market analysis, and Olympic studies with numerous publications and presentations in these areas. He has an extended experience in working for and research on major sports events, including six Summer and Winter Olympic Games. Dr. Song is the lead researcher who designed and coordinated this interdisciplinary problem-based learning project, and was also responsible for data collection and analysis. The project was conducted in a Sport Marketing class he taught. He is the principal writer of the manuscript.

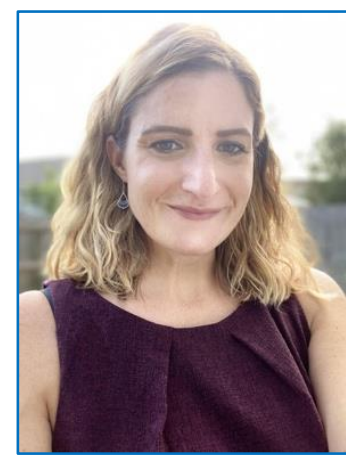

Dr. Heather Riddell earned her Ph.D. in Strategic Communication from George Mason University and a Master's degree in Professional Communication from Clemson University. She is currently an assistant professor of social media communication at the University of West Florida. Her research interests include digital and social media, crisis communication, pedagogy, and public relations. Dr. Riddell was the co-designer and the communication expert for this interdisciplinary problem- based learning project. She conducted the communication workshop and provided feedback to students as the principal evaluator for students' performances. She is the cowriter of the manuscript with her expertise to construct the theoretical framework that supports this research. 


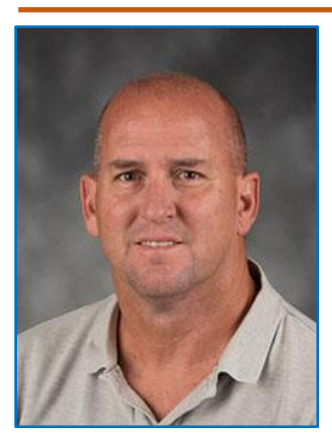

Dr. Stu Ryan is a professor in the Department of Teacher Education \& Educational Leadership at the University of West Florida. Dr. Ryan created many children's fitness and health related curricula and materials to assist classroom teachers. He is recognized as an expert in childhood obesity, and has numerous international, national, regional, and state publications and presentations related to children's health issues. Dr. Ryan acted as the pedagogical expert in this interdisciplinary problem-based learning project who oversaw the design of this research and reviewed the manuscript to ensure its overall quality.

\section{Introduction}

A goal of general education in colleges and universities is to equip students with the fundamental knowledge they will need before moving into more specified courses related to their chosen major [1-4]. The general education courses should emphasize the interdisciplinary connections between concepts and assignments. As students advance into their degree plan, the emphasis on interdisciplinary approaches may get lost $[1,3,5]$. There is a need to continue to emphasize the value of skills from other disciplines as college graduates enter the workforce $[1,6]$. The continued inclusion of interdisciplinary opportunities past the general education requirements can produce higher critical thinking levels needed for various industries $[1,4,6,7]$.

One area of emphasis for all majors and industries is communication and group presentation skills. Students take a basic speaking course, and for many, that is the only emphasis on communication skills that they will receive, even though students may be required to do multiple presentations in classes for their major [5]. The communication training the students receive may not be enough to equip students with the skills they need to be successful and therefore, an emphasis on communication should occur throughout the student's degree plan and not just to satisfy a general education requirement $[2,8]$. Specific classes that present tailored communication opportunities related to industry can help synthesize the skills learned in the general education courses with the concepts from the students' majors $[9,10]$.
This study takes on this interdisciplinary challenge and paired communication faculty with sport management faculty to leverage a class project to further the students' understanding of sport management and underscored the role of effective communication in the sports industry. DeSensi et al. (1990) discussed the sport management curricular needs and concluded that communication skills are the most important skillset for students as they move into the sport management field [11]. Škorić (2018) also identified communication and information management as a top challenge for the field [12]. The Best Colleges for Sport Management Careers (2020) listed communication skills at the top among five skills gained from a sport management degree [13]. This pedagogical experiment aims to determine if an interdisciplinary, problem-based learning opportunity applied to teaching sport marketing aids in the improvement of students' individual and group oral communication skills.

\subsection{Integrating Problem-Based Learning}

The interdisciplinary group of faculty members collaborated to create a problem-based learning (PBL) opportunity that would facilitate the development of sport management learning objectives and reaffirm the need for communication skills to develop students entering the competitive sport management industry [14]. The problem or case used for the PBL opportunity focused on the local minor league baseball stadium that also hosts the university football home games. The stadium was built in 2009 and began to be used for the football team in 2016. Since the stadium was not designed as a football facility, this provides an opportunity to research how well the facility is serving the needs of fans who attended the games. For sport management students, this provides a tangible and familiar opportunity to analyze fan satisfaction and suggest solutions that can potentially be implemented for improving the game services. The areas of fan satisfaction on arrival experience, concession, venue environment, venue technology, game entertainment, and overall game experience are assigned to groups to help focus this problem-based learning assignment and produce a focused analysis and final product.

\subsection{Problem-Based Learning Design}

The hands-on class project allowed the course to be designed around the introduction, formative assessment, lecture intervention, and final PBL deliverable. The faculty spent time introducing the 
students to the fan satisfaction survey and the class project. The students also received data analysis instruction and were tasked with creating a presentation that identifies key issues for fans and then suggest the changes that could be made to resolve the issues. These tasks satisfy the active participation and collaboration requirements that create key learning opportunities in this PBL design. The first presentation acted as a benchmark for the data analysis for this study and the way the students have organized their presentations. The level of analysis is reviewed along with presentation skills like slide design, group speaking skills, and eye contact, which creates an interdisciplinary focus on the construction of the final PBL deliverable.

\subsection{Formative Assessment and Intervention}

After the initial presentation, the communication faculty provides an intervention for the students by conducting a lecture on essential presentation skills needed to make their final presentation more successful. In addition to the lecture intervention, groups were required to review their feedback from the faculty evaluators, and watch a video replay of their group presentation to complete a self-reflection on his/her performance. After receiving all of this information, the students have several weeks to integrate the information into their final presentation.

The PBL case and the interdisciplinary approach allow for additional insight into pedagogical techniques used in a higher education setting. The goal of this study was to determine if the formative assessment and interdisciplinary approach to problembased learning resulted in greater development of students' data analysis and communication skills.

\section{Literature Review}

\subsection{Problem-Based Learning}

The situation in this interdisciplinary collaboration included a class project that was designed to be a problem-based learning opportunity. Several features can qualify a project as a problembased learning opportunity, including an authentic problem, learner autonomy, active exploration in the project, collaboration, assessment, and final project assessment $[15,16]$. In this case, identifying fan satisfaction concerns is an authentic problem and an industry situation that can fulfill a purpose for the stadium operations. In addition, this PBL connected students to a real problem where their findings and suggestions can be implemented due to the university and community relationship. This project design focused on the learning itself and not just the production of a solution or implementation strategies $[7,14,17]$. In classifying the case used for this study, the authentic problem is a qualifying factor in constructing a PBL opportunity [16]. The interdisciplinary component was integrated to emphasize the need for strong communication skills, which are needed to effectively convey the findings and action points to a potential client or department.

Thus, the structure and the design of the course was PBL and not project-based learning (PjBL) [7]. This paper confirms a continuum of problem-based learning that integrates interdisciplinary approaches while producing a tangible product and a clearly structured case instead of an ill-structured case as commonly seen in PBL literature $[7,18]$.

One element that makes PBL so effective in the classroom is the learner autonomy. Students experience instruction on approaching the problem and then collaborating with their group members to solve and construct the required deliverables. PBL research has shown it to be more engaging than traditional learning opportunities $[15,17,19]$. Community partners can also play a role in the development of student engagement [19]. This project partnered directly with the university's athletic department and a community organization.

Additional factors to consider in developing this PBL opportunity included clear formative assessment points that included interdisciplinary interventions. Faculty established rubrics to communicate the PBL expectations to the students prior to the first presentation [15]. The initial rubric was used again to assess the increase in learning after the interdisciplinary intervention. In this case, the assessments throughout the semester are low-risk and promote revision opportunities and deliverable refinement for the group members.

Also, the assessments and intervention allowed the disciplinary silos that students create to be broken down. The project and the presentation components emphasized the need to take skills developed in another area into this project $[10,16]$. The interdisciplinary approach also underscores the role of general education courses and their relevancy in the student degree plan. Students who had already taken a basic communication course were better prepared to complete the PBL than those who had not. The 
emphasis on communication skills also approached the sport management industry more holistically and is more reflective of the skills needed in the workplace $[9,11,14,20]$.

\subsection{Additional Pedagogical Foundations}

In addition to the PBL opportunity, key pedagogical concepts like pragmatism and Bloom's Taxonomy were used to create a learning environment that did not just focus on the data analysis and solutions detailed in the presentations but on concept and skill development. The focus on the learning process and understanding how to approach a survey and analyze the data for actionable outcomes is a skillset most sport management students will use in the industry [22]. Students watched how other students analyzed and presented their data throughout the first round of presentations adding additional vicarious learning opportunities.

The pedagogical foundation in pragmatism is essential as it emphasizes student experience. Dewey (1938) writes extensively about the importance of experience in the learning process [22]. The theory of experience highlights action as a key in developing a learner's mind as learning is not passive [22]. Also, PBL is related to Dewey's concept of 'problem-method' in the inclusion of cases as learning opportunities [22, 23]. In this $\mathrm{PBL}$, students exhibit autonomy from the faculty as they work together in groups to analyze the data, come up with solutions, and design a presentation. The students' previous experiences help them actively engage with the task and create solutions to the issues identified by the survey [23, 24]. The combination of student experience and PBL created a more robust learner experience that achieves higher Bloom's Taxonomy levels, such as analysis, evaluation, and creation. Together, Dewey's theory of experience and Bloom's Taxonomy create a robust learning environment that uses student experience as the springboard to new learner developments and skill attainment. This study's secondary goal was to determine if focusing the PBL deliverables on the higher levels of the taxonomy leads to more significant learning objective achievement [25].

\subsection{Kolb's Learning Cycle}

This study's final pedagogical component leans theoretically on Kolb's Learning Cycle [26] that explains how learning is achieved through four perspectives: experience, observation, conceptualization, and experimentation. The central focus of Kolb's
Experiential Learning Theory suggests that learning is a cycle wherein most people understand concepts better when the message and/or concept is presented from these four perspectives. Structuring the project in this cycle allowed for longitudinal data to be gathered during the initial presentation to be compared to the final presentation scores [27]. (In between the two stages of presentations, instructors may create selfevaluations to prompt students to think about what they have learned about speaking and about themselves as speakers [28]. LeFebvre \& LeFevre (2018) implemented video replay and self-reflections for assessing students' speeches as part of the basic communication course with mixed findings, and suggested that the self-evaluation process is fertile ground for future exploration into student selfevaluation via the data contained in the video to actuate performance improvement for speaking occasions $[29,30]$.

\subsection{Interdisciplinary Objectives}

The final area that guided the development of this study and the design of the PBL was the inclusion of interdisciplinary collaboration and concepts. There was an emphasis on the data analysis and creation of solutions throughout the sport management course, but the communication of that information was a key message emphasis. The group communication scores looked at several concepts overall, and then detailed information was given for each speaker. The emphasis on group presentation and individual communication was an important distinction to help each group member see their contribution to the presentation overall. Group presentation skills were also touched on during the lecture intervention and emphasized group presentation organization structures like the bookend approach or the panel approach [31].

The self-reflection and presentation concepts were taken straight from basic communication learning objectives and focused on the introduction, body, and conclusion of the presentation [32]. The finer points of speech delivery like nonverbals, signposts, and concluding statements were integrated to make the interdisciplinary focus true to what would be expected in a public speaking course. The feedback and selfevaluation formats were modeled from explanatory speech rubrics and forms found in a basic communication course textbook by Valenzano et al. (2015) [31]. The inclusion of communication concepts created an interdisciplinary challenge as students were 
evaluated by both the data analysis level and the quality of the presentations.

This literature on learning objectives, PBL, and communication skills lead to the following hypotheses:

Ho1: There was no difference between the evaluators' scores on students' group communication skills from the first to the second round of research presentations.

Ho2: There was no difference between the evaluators' scores on students' individual communication skills from the first to the second round of presentations.

Ho3: There was no difference between the self-reflection scores from the first to the second round of presentations.

\section{Method}

\subsection{Survey Instrumentation}

To facilitate this study, three evaluation forms on students' communication skills were adopted. The evaluation forms included the Group Presentation Rubric and the Oral Communication Skills rubric, provided by the university's Quality Enhancement Plan (QEP) office, whose mission is to improve students' professional communication skills across all academic disciplines. Two faculty members, one from the communication department and the other in sport management, acted as the evaluators (excluding the course instructor).
They evaluated students' presentation skills and content mastery in both group and individual performance based on these forms. The third form was the Presentation Self-Reflection modeled from the basic communication course curriculum and was voluntarily completed by the students after each round of sport market research presentations.

\subsection{Survey Participants and Procedure}

The participants were thirty-six junior and senior students enrolled in a three-credit hour Sport Marketing class at a regional comprehensive university. The project proposal was reviewed and approved by the university's QEP office and Institutional Review Board (IRB). The study was conducted through a sport market research project that emphasized experiential and high-impact learning objectives. The procedure of this pedagogical experiment is illustrated in Figure 1.

The faculty gave the assignment to the students on the third week of the semester after lecturing and discussing sport market research. The students voluntarily signed up into ten presentation groups consisting of three to four individuals in each group. There were five sets of fan satisfaction survey data collected from the university's previous season home football games. Each of the five data sets was randomly assigned to two (2) project groups for data analysis and presentations.

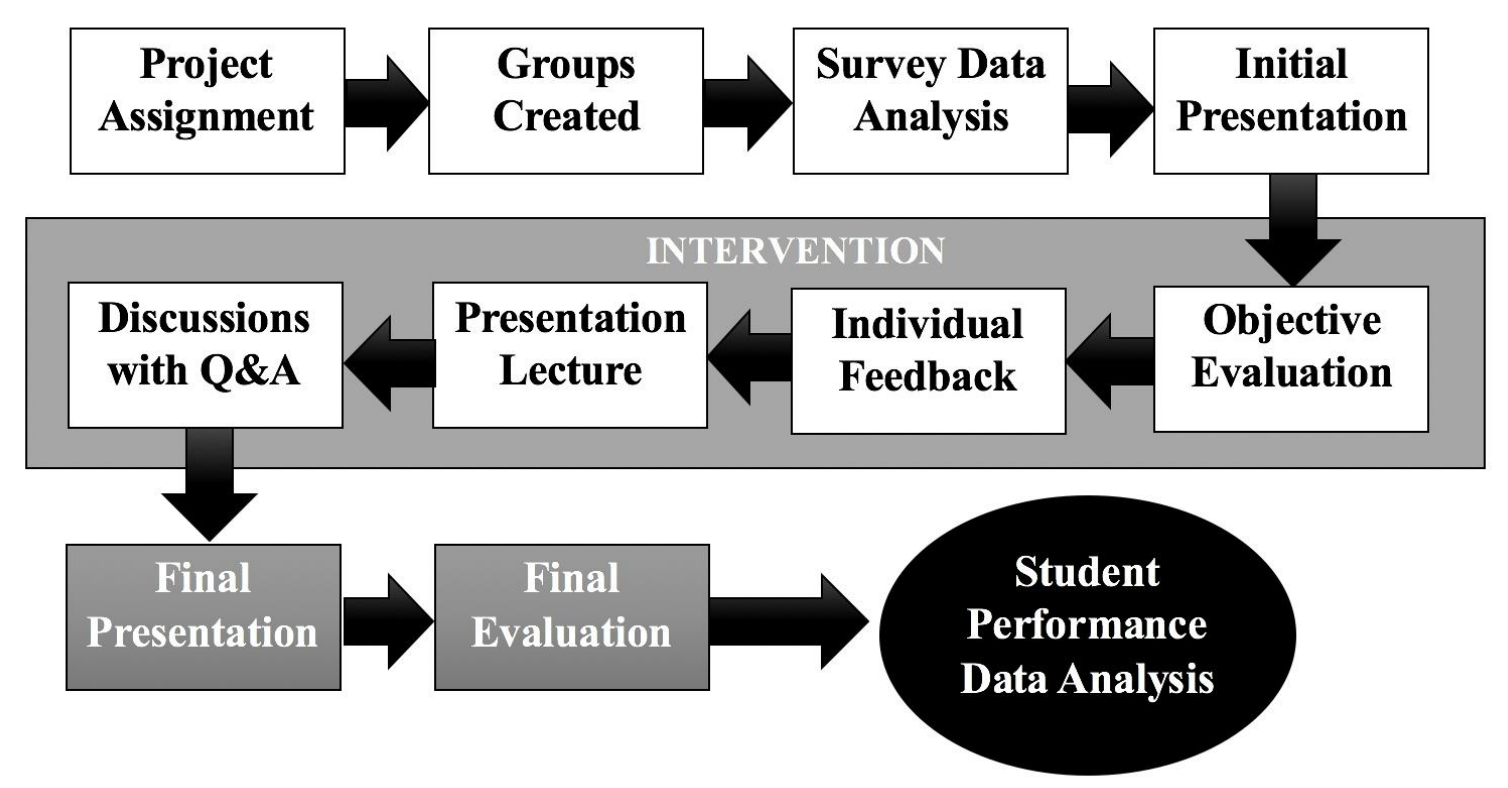

Figure 1 Pedagogical Experiment Procedure 
The assignment requirements were provided to the students, both orally in the classroom, aided by a PowerPoint presentation and a written instruction posted on the course's learning management site (LMS). The presentations were recorded and edited with a viewing unit for each project group and were posted on the course's LMS site for the students to review to complete the Presentation Self-Reflection form. The first round of presentations was conducted four weeks after the assignment was given. Each group had a maximum of fifteen minutes for a PowerPoint presentation, including questions and answers. Immediately following the presentations, the faculty provided the students with the evaluators' feedback on (1) the group presentation performance, (2) each individual's performance, and (3) the taped group presentation videos. A communication skill workshop was conducted by the communication faculty expert the next week following the initial presentations. Before the workshop, the students were required to review the group presentation video and the evaluator's feedback. They were also asked to voluntarily fulfill the Presentation Self-Reflection form. The workshop lasted one hour and fifteen minutes consisting of three sessions - a lecture on professional presentation and communication skills given by the communication expert (faculty), group discussions based on the lecture and the evaluators' feedback, and a question/answer session.

The second round of research presentations was conducted three weeks after the communication workshop. The students presented their second presentations with the same set of sports fan satisfaction data aiming to improve the data analysis and communication skills based on the evaluators' feedback and the information received in the communication workshop. The evaluators again provided their feedback to the students on their group and individual performance from the second-round presentations. The students were also provided with the video on their group presentations for selfreflection purposes.

\subsection{Data Collection and Analysis}

The collected data for this study consists of three sets of evaluation scores from the first round of research presentations before the communication workshop and from the second round of presentations after the workshop - (1) group presentation skills, (2) individual presentation skills, and (3) self-reflections. Thirty-five students participated in each round of group presentations. Two individuals missed their group presentations, with one in the first round and another in the second round. Coincidently, twenty-one students, equivalent to $60 \%$ of the total participants in group presentations, voluntarily submitted their selfreflection forms after each round of presentations with six different students from the first to the second round and the same fifteen students in both rounds.

This study's primary objective was to examine the improvement of students' data analysis and presentation skills from the first to the second round of sport market research presentations with the intervention of a communication workshop provided by the faculty expert. The two rounds of presentations went beyond the usual practice for a sport market research assignment that requires only one round of presentations.

Analyzing the data collected from two rounds of presentations, the Paired Sample $t$-Test was adopted to test the following hypotheses. Ho1: There was no difference between the evaluators' scores on students' group communication skills from the first to the second round of research presentations; Ho2: There was no difference between the evaluators' scores on students' individual communication skills from the first to the second round of presentations; and Ho3: There was no difference between the selfreflection scores from the first to the second round of presentations. The Paired Sample t-Test was also applied to check the consistency of two evaluators' scores. Due to relatively small population size in this study, a $95 \%$ probability was employed to test the hypotheses for significance.

\section{Results}

\subsection{Group Presentation Skills}

The Paired Sample t-Test results are from the Group Presentation Rubric scores between the first and the second round of students' presentations depict a significant improvement in their communication skills as displayed in Table 1.

Among the four criteria of content, collaboration, organization, and presentation that measure the group presentation skills, three of them indicate significant improvement except for organization. In fact, students did well in organizing their presentations even in the first round of presentations with a mean of 3.13 on a 4.0 scale. The mean score for the second round of presentations is 3.43, an improved score without statistical significance. The means for the second round of presentations for 
content, collaboration, and presentation are 3.05, 3.48, and 3.18, improved from the first round of 2.50, 2.88, and 2.53 , respectively.

\subsection{Individual Presentation Skills}

There are seven (7) indicators measuring the individual oral communication skills in the form of Oral Communication Skills, as displayed in Table 2. The results of mean scores for individual oral communication skills depict an overall improvement from the first to the second round of presentations at the significant level of $\llbracket p \rrbracket \wedge(\leq .01)$ for each measured criterion. The scoring of the evaluation for individual oral communication skills uses the scale of 0 , 1 , and 2 representing from the lowest to highest rated skills. The mean scores of the seven measured skills in the first round of presentations were between 1.0 and 1.26 and were improved to between 1.35 to 1.62 in the second round of presentations.

\subsection{Self-Reflections}

The students' self-reflection of their presentation skills consists of five categories with sixteen traits/content indicators, as displayed in Table 3. The scoring scale is from 0 to 4 , with a one-point interval to indicate the self-rating from the lowest to the highest.

The mean scores of self-reflections had a cross board improvement with statistical significance from the first to the second round of presentations except for one content indicator, "Recommendations" in the category of "Body," although the mean score of this indicator improved from 3.0 to 3.38. Among the fifteen improved trait/content indicators, ten of them reached a significant level of $\llbracket p \rrbracket \wedge(\leq .01)$ beyond the significant level of $\llbracket p \rrbracket \wedge(\leq .05)$ set for this study.

Table 1 Paired t-Test for Group Presentation Skills

\begin{tabular}{|l|c|c|}
\hline \multicolumn{1}{|c|}{ Presentation Skills } & $\begin{array}{c}1 \text { st vs 2nd } \\
\left(\bar{X}_{1}\right)\end{array}$ & $\begin{array}{c}t \\
(\mathrm{df}=19)\end{array}$ \\
\hline $\begin{array}{l}\text { Content: Did the presentation have valuable material and } \\
\text { address the reflection questions? }\end{array}$ & $\bar{X}_{1}<\bar{X}_{2}$ & $-3.240^{* *}$ \\
\hline $\begin{array}{l}\text { Collaboration: Did everyone contribute to the } \\
\text { presentation? Did everyone seem well versed in the } \\
\text { material? }\end{array}$ & $\bar{X}_{1}<\bar{X}_{2}$ & $-2.698^{*}$ \\
\hline $\begin{array}{l}\text { Organization: Was the presentation well organized and } \\
\text { easy to follow? }\end{array}$ & $\bar{X}_{1}<\bar{X}_{2}$ & -1.878 \\
\hline $\begin{array}{l}\text { Presentation: Did the presenters speak clearly? Did they } \\
\text { engage the audience? Was it obvious the material had been } \\
\text { rehearsed? }\end{array}$ & $\bar{X}_{1}<\bar{X}_{2}$ & $-4.466^{* *}$ \\
\hline
\end{tabular}

$\bar{X}_{1}=$ Mean of the evaluators' scores for the first presentation; $\bar{X}_{2}=$ Mean of the evaluators' scores for the second presentation.

$* p \leq .05 ; * * p \leq .01$

Table 2 Paired t-Test for Individual Presentation Skills

\begin{tabular}{|c|c|c|}
\hline Presentation Skills & $\begin{array}{l}\text { 1st vs 2nd } \\
\left(\bar{X}_{1}\right) \quad\left(\bar{X}_{2}\right)\end{array}$ & $\begin{array}{c}t \\
(\mathrm{df}=69)\end{array}$ \\
\hline Uses sources that are appropriate and relevant & $\bar{X}_{1}<\bar{X}_{2}$ & $-4.770 * *$ \\
\hline Pronunciation and diction are generally error-free & $\bar{X}_{1}<\bar{X}_{2}$ & $-4.498 * *$ \\
\hline Exhibits standard rules of grammar, tone, volume, and tempo & $\bar{X}_{1}<\bar{X}_{2}$ & $-3.210 * *$ \\
\hline $\begin{array}{l}\text { Language and content serve the intended purpose of the } \\
\text { communication. }\end{array}$ & $\bar{X}_{1}<\bar{X}_{2}$ & $-6.478 * *$ \\
\hline Uses language, jargon tailored to audience understanding. & $\bar{X}_{1}<\bar{X}_{2}$ & $-5.191 * *$ \\
\hline $\begin{array}{l}\text { States a clear conclusion that is consistent with the evidence } \\
\text { presented. }\end{array}$ & $\bar{X}_{1}<\bar{X}_{2}$ & $-3.472 * *$ \\
\hline Presents communication with a professional level of polish. & $\bar{X}_{1}<\bar{X}_{2}$ & $-5.627 * *$ \\
\hline
\end{tabular}

$\bar{X}_{1}=$ Mean of the evaluators' scores for the first presentation; $\bar{X}_{2}=$ Mean of the evaluators' scores for the second presentation.

$* p \leq .05 ; * * p \leq .01$ 
Table 3 Paired t-Test for Students' Self-Reflection from First to Second Presentation

\begin{tabular}{|c|c|c|}
\hline \multirow[t]{2}{*}{ Trait/Content } & 1st vs 2nd & \multirow{2}{*}{$\begin{array}{c}t \\
(\mathrm{df}=20)\end{array}$} \\
\hline & $\left(\bar{X}_{1}\right) \quad\left(\bar{X}_{2}\right)$ & \\
\hline \multicolumn{3}{|l|}{ Introduction } \\
\hline $\begin{array}{l}\text { Attention-getter is present, introduces the topic, and } \\
\text { sparks information hunger. }\end{array}$ & $\bar{X}_{1}<\bar{X}_{2}$ & $-2.751^{* *}$ \\
\hline $\begin{array}{l}\text { Thesis - there is a clear, declarative statement on } \\
\text { the topic and direction of the presentation. }\end{array}$ & $\bar{X}_{1}<\bar{X}_{2}$ & $-2.855^{* *}$ \\
\hline $\begin{array}{l}\text { Preview of main points - the speaker highlights the } \\
\text { main points to be discussed in the rest of the } \\
\text { presentation. }\end{array}$ & $\bar{X}_{1}<\bar{X}_{2}$ & $-2.609 * *$ \\
\hline \multicolumn{3}{|l|}{ Body } \\
\hline $\begin{array}{l}\text { Each main point of the body was clearly stated and } \\
\text { contained beneficial insights into the data. }\end{array}$ & $\bar{X}_{1}<\bar{X}_{2}$ & $-4.183^{* *}$ \\
\hline $\begin{array}{l}\text { Transitions - the speaker clearly indicated when } \\
\text { they were moving from one point to the next. }\end{array}$ & $\bar{X}_{1}<\bar{X}_{2}$ & $-4.954 * *$ \\
\hline $\begin{array}{l}\text { Quality of data - data is analyzed thoroughly to set- } \\
\text { up an insightful discussion of proposed } \\
\text { recommendations. }\end{array}$ & $\bar{X}_{1}<\bar{X}_{2}$ & $-3.347 * *$ \\
\hline $\begin{array}{l}\text { Recommendations - the recommendations provided } \\
\text { are a direct result of the data presented and connect } \\
\text { to specific areas of low experience ratings. }\end{array}$ & $\bar{X}_{1}<\bar{X}_{2}$ & -1.896 \\
\hline \multicolumn{3}{|l|}{ Conclusion } \\
\hline $\begin{array}{l}\text { Signposts - speaker signals they are moving into the } \\
\text { conclusion with a clear signpost like "In conclusion" } \\
\text { or "finally." }\end{array}$ & $\bar{X}_{1}<\bar{X}_{2}$ & $-2.107^{*}$ \\
\hline $\begin{array}{l}\text { Reviews main points - speaker goes over what they } \\
\text { presented using concise language. }\end{array}$ & $\bar{X}_{1}<\bar{X}_{2}$ & $-4.483 * *$ \\
\hline $\begin{array}{l}\text { Memorable closer - speaker brings the speech to a } \\
\text { close with a statement that leaves the audience with } \\
\text { a sense of understanding and closure. }\end{array}$ & $\bar{X}_{1}<\bar{X}_{2}$ & $-4.315^{* *}$ \\
\hline \multicolumn{3}{|l|}{ PowerPoint } \\
\hline $\begin{array}{l}\text { Presentation aid has a clear design with strong } \\
\text { contrasting colors and large, easily-readable fonts. }\end{array}$ & $\bar{X}_{1}<\bar{X}_{2}$ & $-3.200 * *$ \\
\hline $\begin{array}{l}\text { Chart information is labeled correctly without } \\
\text { additional explanation. }\end{array}$ & $\bar{X}_{1}<\bar{X}_{2}$ & $-2.335^{*}$ \\
\hline $\begin{array}{l}\text { Chart information is explained in the presentation } \\
\text { and is integrated in a meaningful way. }\end{array}$ & $\bar{X}_{1}<\bar{X}_{2}$ & $-3.516^{* *}$ \\
\hline \multicolumn{3}{|l|}{ Delivery } \\
\hline $\begin{array}{l}\text { Speaker was able to give their part of the } \\
\text { presentation without relying heavily on notes or the } \\
\text { information on the PowerPoint. }\end{array}$ & $\bar{X}_{1}<\bar{X}_{2}$ & $-2.586 *$ \\
\hline $\begin{array}{l}\text { Eye contact was made throughout with only minor } \\
\text { glances at notes or PowerPoint. }\end{array}$ & $\bar{X}_{1}<\bar{X}_{2}$ & $-2.137 *$ \\
\hline $\begin{array}{l}\text { Nonverbal - gestures were used appropriately to } \\
\text { highlight points. No extra movement or swaying } \\
\text { occurred. Speaker faced the audience and not the } \\
\text { projector screen. }\end{array}$ & $\bar{X}_{1}<\bar{X}_{2}$ & $-2.444 *$ \\
\hline
\end{tabular}

$\bar{X}_{1}=$ Mean of the first presentation scores; $\bar{X}_{2}=$ Mean of the second presentation scores.

$* p^{\leq .05} ; * * p^{\leq .01}$ 


\subsection{Scoring Consistency}

Two faculty evaluators evaluated the students' presentations using the forms of Group Presentation Rubric and Oral Communication Skills provided by the university's Quality Enhancement Plan (QEP) office that was missioned to improve students' professional communication skills as previously explained in the section of the survey instrument and procedure. The consistency tests of the evaluators' scores measuring both the group and individual presentation skills were conducted using the Paired Sample t-Test method.

Both evaluators' mean scores indicate a statistical consistency without significant differences in scoring all four indicators for the group presentation skills, as shown in Table 4. The evaluators scored the students' individual presentation skills with some degree of inconsistency, as Table 5 displays. It is observed that the evaluators agreed more on the general presentation skills assessed by the first three skill measures but less on the sport marketing content related presentation skills assessed by the last four skill measures.
The first three measures are specifically for general communication skills that were not directly linked to the presentation's sport marketing content. Although the mean scores from both evaluators are consistent for these skill measures, there is a trend that the communication expert had a higher expectation for the students' performance on oral presentation skills than the sport management faculty $\operatorname{did}\left(X_{-}^{-} 1<X_{-}^{-} 2\right)$. The inconsistency of the evaluators' scoring was from the last four measured skills. It is interesting to observe the tendency of each evaluator on scoring these skills that is the communication expert scored in a lower average on measures $\left(X_{-}^{-} 1<X_{-}^{-} 2\right)$ unrelated to the sport marketing content (fourth and seventh measures), and in contrast, the sport management faculty scored the students with a lower average $\left(X_{-}^{-} 1>X_{-}^{-} 2\right)$ on the sport marketing content related measures (fifth and sixth). It appears that each faculty evaluator had a higher expectation from the students on their knowledge expertise.

Table 4 Paired t-Test for the Evaluators' Scores on Group Presentation Skills

\begin{tabular}{|l|c|c|}
\hline \multicolumn{1}{|c|}{ Presentation Skills } & $\begin{array}{c}1 \text { st vs 2nd } \\
\left(\bar{X}_{1}\right)\end{array}$ & $\begin{array}{c}t \\
(\mathrm{df}=19)\end{array}$ \\
\hline $\begin{array}{l}\text { Content: Did the presentation have valuable material and } \\
\text { address the reflection questions? }\end{array}$ & $\bar{X}_{1}>\bar{X}_{2}$ & .326 \\
\hline $\begin{array}{l}\text { Collaboration: Did everyone contribute to the presentation? } \\
\text { Did everyone seem well versed in the material? }\end{array}$ & $\bar{X}_{1}>\bar{X}_{2}$ & 2.39 \\
\hline $\begin{array}{l}\text { Organization: Was the presentation well organized and easy } \\
\text { to follow? }\end{array}$ & $\bar{X}_{1}>\bar{X}_{2}$ & .302 \\
\hline $\begin{array}{l}\text { Presentation: Did the presenters speak clearly? Did they } \\
\text { engage the audience? Was it obvious the material had been } \\
\text { rehearsed? }\end{array}$ & $\bar{X}_{1}=\bar{X}_{2}$ & .000 \\
\hline
\end{tabular}

$\bar{X}_{1}=$ Mean of the first evaluator's scores; $\bar{X}_{2}=$ Mean of the second evaluator's scores.

$* p \leq .05 ; * * p \leq .01$

Table 5 Paired t-Test for the Evaluators' Scores on Individual Presentation Skills

\begin{tabular}{|l|c|c|}
\hline \multicolumn{1}{|c|}{ Presentation Skills } & $\begin{array}{c}1 \text { st vs 2nd } \\
\left(\bar{X}_{1}\right)\left(\bar{X}_{2}\right)\end{array}$ & $\begin{array}{c}t \\
\text { (df =69) }\end{array}$ \\
\hline Uses sources that are appropriate and relevant & $\bar{X}_{1}<\bar{X}_{2}$ & -1.618 \\
\hline Pronunciation and diction are generally error-free & $\bar{X}_{1}<\bar{X}_{2}$ & -.225 \\
\hline Exhibits standard rules of grammar, tone, volume, and tempo & $\bar{X}_{1}<\bar{X}_{2}$ & -1.953 \\
\hline $\begin{array}{l}\text { Language and content serve the intended purpose of the } \\
\text { communication. }\end{array}$ & $\bar{X}_{1}<\bar{X}_{2}$ & $-2.116^{*}$ \\
\hline Uses language, jargon tailored to audience understanding. & $\bar{X}_{1}>\bar{X}_{2}$ & $-3.426^{* *}$ \\
\hline $\begin{array}{l}\text { States a clear conclusion that is consistent with the evidence } \\
\text { presented. }\end{array}$ & $\bar{X}_{1}>\bar{X}_{2}$ & $-3.472^{* *}$ \\
\hline Presents communication with a professional level of polish. & $\bar{X}_{1}<\bar{X}_{2}$ & $-5.627^{* *}$ \\
\hline
\end{tabular}

$\bar{X}_{1}=$ Mean of the first evaluator's scores; $\bar{X}_{2}=$ Mean of the second evaluator's scores.

$* p \leq .05 ; * * p^{\leq .01}$ 


\section{Discussion}

This study aimed to determine the effectiveness of an interdisciplinary approach to problem-based learning that may result in greater development of students' data analysis and presentation skills. The design of this pedagogical experiment was rested on the foundation and framework of PBL Lee et al., 2014, Dewey's theory of experience (1938), Kolb's experiential learning theory (1984), and the interdisciplinary approaches to learning $[1,15,22,26]$. This experiment's design also intended to offer the students an opportunity to master and apply professional knowledge in sport marketing through an interdisciplinary approach across communication and sport management.

The study results from the Group Presentation Rubric and Oral Communication Skills indicate a successful development of the students' data analysis and presentation skills, and therefore, rejects the hypotheses that there is no difference between the evaluations of the students' group presentations and the individual communication skills from the first to the second round of research presentations ( $\mathrm{Ho} 1$ and $\mathrm{Ho} 2$, respectively). The results reaffirm the fitness of this pedagogical experiment design to reflect the four perspectives of Kolb's (1984) experiential learning: experience (the initial presentation), observation (the guest lecture), conceptualization (the evaluators' feedback and self-reflection), and experimentation (the final presentation) [26]. Strokes-Eley (2007) summarized that "Structuring the project in this cycle allowed for longitudinal data to be gathered during the initial presentation to be compared to the final presentation scores [27]." The PBL design of this experiment aligns with the defined process for interdisciplinary study of a given problem suggested by Hursh et al. (1983) in their work of an interdisciplinary model that was witnessed by the students' improvement through the three measuring tools used in this study [1]. The overall success of this pedagogical experiment was proved with the improvement of students' presentation skills along with their mastery of sport market research in this PBL assignment.

The conceptualization in this experiment was accomplished through students' review of the evaluators' feedback and the intervention of the faculty expert's communication workshop. The faculty expert summarized the students' performance on their initial presentations and redirected their effort on improving the under-performed research and communication skills in the workshop. The students' self-reflections, after reviewing the presentation video, also helped achieve the objective of conceptualization. The cross the board improvement on each examined item on Presentation Self-Reflection form in this study provides another positive evidence of implementing the video replay and self-reflections for assessing students' communication skills suggested by LeFebvre \& LeFebvre (2018) and Barry (2012) [29, 30]. This evidence profoundly rejects the third hypothesis (Ho3) that there was no difference between the selfreflection scores from the first to the second round of presentations.

Although this pedagogical experiment offers a piece of encouraging evidence to use PBL, Kolb's Experiential Learning Model, and video plus selfreflection technique to assist student learning of subject matter and improving their presentation skills, the challenge comes from a collaborated effort of teaching faculty across the academic disciplines. In other words, the interdisciplinary cooperation demands out of ordinary teaching routine in any current existing institutional environment to support such an effort. For the sake of the best student learning experience and outcomes, this kind of extraordinary effort could be worthwhile.

\section{Conclusion}

It is essential for sport managers and athletic directors to possess proficient management skills in order to meet the increasing industrial demands for quality professionals in the sport industry. Communication, as one of the sport management functions, is enlisted in the Commission on Sport Management Accreditation [33] recommended common professional component for a sport management curriculum. Training sport management students' communication skills, including the presentation skills, may present a pedagogical challenge. However, the results of this study imply that the interdisciplinary and problem-based learning may be a useful method to enhance the teaching effectiveness for improving sport management students' communication skills.

\section{References}

[1] B. Hursh, P. Haas, \& M. Moore, An interdisciplinary model to implement general education, The Journal of Higher Education, 54(1) (1983) 42-59. [DOI] 
[2] J.T. Klein, A platform for a shared discourse of interdisciplinary education, Journal of Social Science Education, 5(4) (2006) 10-18. [DOI]

[3] T.F.N. Laird, \& A.K. Garver, The effect of teaching general education courses on deep approaches to learning: How disciplinary context matters, Research in Higher Education, 51(3) (2010) 248-265. [DOI]

[4] L.R. Lattuca, L.J. Voigt, \& K.Q. Fath, Does interdisciplinarity promote learning? Theoretical support and researchable questions. The review of Higher Education, 28(1) (2004) 23-48. [DOI]

[5] Y. Weiberger, Two Birds, One Stone: Integrating Communication Proficiency Development into Existing Academic Courses, Journal of Educational Research and Practice, 8(1) (2018) 9. [DOI]

[6] K. Nisula, \& S. Pekkola, How to move away from the silos of business management education?, Journal of Education for Business, 93(3) (2018) 97-111. [DOI]

[7] M. Brassler, \& J. Dettmers, How to enhance interdisciplinary competence - interdisciplinary problem-based learning versus interdisciplinary project-based learning, Interdisciplinary Journal of Problem-Based Learning, 11(2) (2017). [DOI]

[8] L.A. Stern, \& M. Hailer, Presentation skills: An assessment of university and career-related presentations, Basic Communication Course Annual, 19(1) (2007)

10. http://ecommons.udayton.edu/bcca/vol19/iss1 $\angle 10$

[9] J.R. Braunstein-Minkove, \& J.R. DeLuca, Effectively adapting the sport management curricula: Harnessing internal and external resources to address industry-specific needs, Schole: A Journal of Leisure Studies and Recreation Education, 30(2) (2015) 12-30. [DOI]

[10] E.A. Ilgar, \& B.B. Cihan, A Phenomenological Analysis on Evaluation of Sports Management Department Curriculum by Sports Sciences Faculty Members, Journal of Curriculum and Teaching, 7(2) (2018) 139-150. [DOI]

[11] J.T. DeSensi, D.R. Kelley, M.D. Blanton, \& P.A. Beitel, Sport management curricular evaluation and needs assessment: A multifaceted approach, Journal of Sport Management, 4(1) (1990) 31-58. [DOI]
[12] S. Škorić, (2018, May). Characteristics of sport managers and challenges facing sport organizations. In 9th International Conference "An enterprise odyssey: Managing change to achieve quality development (pp. 497-503). https://bib.irb.hr/datoteka/944150.45Skoric.pdf

[13] Staff Writer (September 2, 2020). Sports Management Careers. Best Colleges. https://www.bestcolleges.com/careers/busines s/sports-management/

[14] D.A. Miragaia, \& J.A. Soares, Higher education in sport management: A systematic review of research topics and trends, Journal of Hospitality, Leisure, Sport \& Tourism Education, 21 (2017) 101-116. [DOI]

[15] J.S. Lee, S. Blackwell, J. Drake, \& K.A. Moran, Taking a leap of faith: Redefining teaching and learning in higher education through projectbased learning, Interdisciplinary Journal of Problem-Based Learning, 8(2) (2014). [DOI]

[16] M. Warr, \& R.E. West, Bridging Academic Disciplines with Interdisciplinary Project-based Learning, Interdisciplinary Journal of ProblemBased Learning, 14(1) (2020). [DOI]

[17] D.D. Sellnow, \& S.L. Ahlfeldt, Fostering critical thinking and teamwork skills via a problembased learning (PBL) approach to public speaking fundamentals, Communication Teacher, 19(1) (2005) 33-38. [DOI]

[18] A.A. Tawfik, W. Hung, \& P.J. Giabbanelli, Comparing how different inquiry-based approaches impact learning outcomes, Interdisciplinary Journal of ProblemBased Learning, 14(1) (2020). [DOI]

[19] M.M. Grant, (2009). Understanding projects in project-based learning: A student's perspective, Paper presented at Annual Meetings of the American Educational Research Association.

[20] S.S. Kumar, Soft skills for sports management, International Journal of Physical Education, Sports and Health, 4(3) (2017) 152153.

[21] B.L. Day, (2020). The Preparation of Sports Managers: A Case Study of Sports Management Program Curriculum Change (Doctoral dissertation, Northcentral University).

https://search.proquest.com/docview/2399740 472?pq-origsite $=$ gscholar\&fromopenview $=$ true

[22] J. Dewey, (1938). Experience and Education. Macmillan, 1959; copyright by Kappa Delta Pi. 
[23] M. Moallem, W. Hung, \& N. Dabbagh, (2019). The Wiley handbook of problem-based learning. John Wiley \& Sons, Inc.

[24] D.R. Krathwohl, \& L.W. Anderson, (2009). A taxonomy for learning, teaching, and assessing: A revision of Bloom's taxonomy of educational objectives. Longman.

[25] B.S. Bloom, M.D. Engelhart, E.J. Furst, W.H. Hill, \& D.R. Krathwohl, (1956). Taxonomy of education objectives: The classification of educational goals, Handbook 1: Cognitive domain. Longman.

[26] D.A. Kolb, (1984). Experiential learning: Experience as the source of learning and development. Prentice-Hall, Inc.

[27] S. Strokes-Eley, Using Kolb's experiential learning cycle in chapter presentations, Communication Teacher, 21(1) (2007) 26-29. [DOI]

[28] E. Kusnic, \& M. Finley, Student self-evaluation: An introduction and rationale, New Directions for Teaching and Learning, 56 (1993) 5-14. [DOI]

[29] L. LeFebvre, \& L.E. LeFebvre, "The eye in the sky doesn't lie": Video replay and selfevaluations as part of the basic communication course, Communication Teacher, 32(3) (2018) 167-178. [DOI]

[30] S. Barry, A video recording and viewing protocol for student group presentations: Assisting self-assessment through a Wiki environment, Computers \& Education, 59(3) (2012) 855-860. [DOI]

[31] J.M. Valenzano, M.A. Broeckelman-Post, \& E.S. Parcell, (2015). Communication Pathways. Fountainhead

Press. https://ecommons.udayton.edu/cmm fac pub/ $\underline{20}$

[32] A. Slagell, Why should you use a clear pattern of organization? Because it works, Communication Teacher, 27(4) (2013) 198-201. [DOI]

[33] Commission on Sport Management Accreditation (2016, May). Accreditation Principles Manual \& Guidelines for Self-study Preparation.

https://www.cosmaweb.org/accreditationmanuals.html
Funding

No funding was received for conducting this study.

\section{Authors Contribution}

All the authors equally contributed to this work and approved the final version of the manuscript.

\section{Ethics Approval}

This study was approved by University's QEP (Quality Enhancement Plan) office and Institutional Review Board (IRB).

\section{Informed Consent}

Written informed consent was obtained from the participants

\section{Conflict of interest}

The Authors have no conflicts of interest to declare that they are relevant to the content of this article.

\section{Does this article screened for similarity? \\ Yes}

\section{About The License}

(C) The Author(s) 2021. The text of this article is open access and licensed under a Creative Commons Attribution 4.0 International License 